\author{
MARÍA DEL CARMEN PAREDES \\ Universidad de Salamanca \\ paredes@usal.es
}

\title{
El alma en la Primera Enciclopedia de Hegel
}

\section{Soul in the First Encyclopedia of Hegel}

RESUMEN: En la primera edición de la Enciclopedia, Hegel presenta su «Filosofía del Espíritu» afirmando: «Para nosotros, el espíritu tiene a la naturaleza como su presupuesto». En esta presentación del paso de la Filosofía de la Naturaleza a la Filosofía del Espíritu reside uno de los puntos de partida principales para la exposición de Hegel sobre el desarrollo del alma. Este desarrollo lleva el sello de su concepción del espíritu como "la verdad de la naturaleza» y de que «la naturaleza ha desaparecido en esta verdad y el espíritu se ha elevado como la Idea» $(\$ 300)$.

PALABRAS CLAVE: ESPÍRITU NATURAL; ALMA; DESPERTAR; CORPOREIDAD
ABSTRACT: In the first edition of the Encyclopaedia, Hegel presents his Philosophy of Spirit stating that «For us spirit has nature as its presupposition». In this claim of transition from the Philosophy of Nature to the Philosophy of Spirit lies one of Hegel's main starting points for his demonstration about the development of the soul. This development is marked by his conception of spirit as the «truth of nature», and that «nature has vanished in this truth, and spirit has yielded itself as the Idea» (\$300).

KEY WORDS: NATURGEIST; SOUL; AWAKING; EMBODIMENT

EN MEMORIA DE MARIANO ÁLVAREZ GÓMEZ

\section{INTRODUCCIÓN}

$\mathrm{E}$

n la CIENCIA DE LA LóGICA encontramos una exposición programática de lo que debe ser el contenido de una Antropología ${ }^{1}$, que Hegel da a conocer en la Enciclopedia de 1817. Antes de esta publicación, la «Filosofía del espíritu» de

[1] Cf. G.W.F. Hegel, Wissenschaft der Logik, GW 12, p. 197. 
Jena $^{2}$ contiene algunos temas de antropología, aunque carecen de una debida sistematización. No obstante, en Jena se perfilan las líneas maestras a partir de las cuales Hegel construiría su exposición en la Enciclopedia.

La Filosofía del Espíritu Subjetivo de 1817 comienza con este planteamiento programático: «El espíritu se puede llamar subjetivo en la medida en que es en su concepto. Y puesto que el concepto es la reflexión de su universalidad a partir de su particularización en sí (in sich), el espíritu subjetivo es: a) el inmediato, el espíritu de la naturaleza (Naturgeist), -el objeto de la llamada antropología o el alma; b) el espíritu como reflexión idéntica en sí y en otro, relación (Verhältnis) o particularización; - conciencia, es decir, el objeto de la fenomenología del espíritu; c) el espíritu que es para sí o en cuanto sujeto - esto es, el objeto de la llamada psicología.- En el alma despierta la conciencia; la conciencia se afirma como razón; y la razón subjetiva se libera a través de su actividad hacia la objetividad $»^{3}$.

A continuación, Hegel introduce el título: «A. El alma» y presenta al espíritu subjetivo en estos términos: «El espíritu ha devenido como la verdad de la naturaleza, que en sí mismo se ha traspuesto y superado. [...] el espíritu devenido tiene, por tanto, el sentido de que la naturaleza se supera en sí misma como lo no-verdadero [...]» (\$308). Esta presentación, a la que sigue el desarrollo progresivo de los contenidos cada vez más concretos, es característica de la concepción hegeliana de la Enciclopedia ${ }^{4}$ así como del despliegue de la unidad entre método y contenido. Acerca de esta unidad, en el último parágrafo de la «Filosofía de la naturaleza» se nos dice que la naturaleza se encuentra "traspuesta en su verdad...en el espíritu» (\$299), con lo que Hegel sitúa la transición de la «Filosofía de la naturaleza» a la «Filosofía del espíritu» en el quicio de la trasposición de la naturaleza hacia su verdad. Asimismo, Hegel afirma que el espíritu subjetivo es el espíritu finito, cuya finitud tiene el significado de la inadecuación entre su concepto y la realidad, de tal modo que «los diversos grados de la actividad del espíritu son los grados de su liberación»(\$306). Esta

[2] Especialmente en G.W.F. Hegel, Systementwurf I (1803/1804) GW 6, pp. 285s y Systementwurf III (1805/1806) GW 8, pp. 186s, 190.

[3] G.W.F. Hegel, Enzyklopädie der Philosophischen Wissenschaften im Grundrisse (1817), hrsg von Wolfgang Bonsiepen und Klaus Grotsch, GW13, Hamburg, cop. 2000, \$307. En adelante se cita esta Enciclopedia dentro del texto.

[4] En el curso 1808/1809, Hegel introdujo su concepto de «enciclopedia» como «la ciencia de la conexión necesaria y determinada por el concepto así como del surgimiento (Entstehung) filosófico de los conceptos fundamentales y de los principios de las ciencias», lo que representa «el contenido general de la filosofía» (TWA4, 9), en el que vienen a fundarse las ciencias no filosóficas. En cursos sucesivos de Nuremberg, Hegel fue perfilando ese contenido, con la estructura tripartita que conocemos. CF. G. Amengual, «La Enciclopedia de las Ciencias Filosóficas», en G. Amengual (ed.), Guía Comares de Hegel, Granada, Comares, 2015, pp. 97ss. 
inadecuación supone que la progresión en los grados de actividad es a la vez un regreso cada vez distinto al origen, esto es, a la naturaleza transformada por la interiorización del espíritu en ella y por la liberación de sus límites. Toda forma de finitud es traspasada a medida que se hace no-verdadera; todo avance es una mediación que libera, y a la vez concreta, el despliegue efectuado. Con estas breves indicaciones, entramos en el tratamiento del alma, que es el concepto central de la Antropología.

\section{LA INMATERIALIDAD DEL ALMA}

La sección del alma (A. $\$ \$ 308-328$ ), se estructura en los siguientes apartados: a. La determinidad natural del alma (\$\$311-318); b. Oposición del alma subjetiva frente a su sustancialidad (\$\$319-325), c. La realidad efectiva del alma (\$\$326-328). Además del alma, el espíritu subjetivo comprende las secciones: B. La conciencia y C. El espíritu. Por consiguiente, alma, conciencia y espíritu no son entidades completamente autónomas, sino estadios de un desarrollo donde el espíritu es el nivel superior, si bien no es algo que aparece al final, sino que en todos ellos el espíritu está presente.

El alma constituye el primer estadio de la filosofía del espíritu subjetivo, en su denominación de espíritu «inmediato» y «espíritu de la naturaleza». Desde una perspectiva fenomenológica, cabría decir que partiendo de las cosas -o desde la experiencia- vamos de la naturaleza al alma y del alma a la conciencia para alcanzar y descubrir (en realidad, redescubrir) el espíritu. ${ }^{5}$ En este desarrollo el alma se presenta ligada a la naturaleza desde diferentes ángulos, como mediación dinámica entre la naturaleza y el espíritu.

La característica primera del alma es su inmaterialidad. En este comienzo, lo que hay de inmaterial en la naturaleza es el alma, que «no es sólo inmaterial para sí, sino la inmaterialidad general de la naturaleza, su simple vida ideal» (\$309). Esto supone, por lo pronto, que la naturaleza es el presupuesto que nos permite hablar en términos de inmaterialidad. Y a la vez que «inmaterialidad general de la naturaleza», el alma es «identidad inmediata de la subjetividad que es en sí (in sich) y de la corporeidad» (\$309). En este sentido, la teoría hegeliana del alma apunta también, si no directamente al menos dentro del conjunto de sus determinaciones, a una filosofía de la corporeidad, que no representa un nuevo modelo de dualismo. Por el contrario, la inmaterialidad del alma se concreta

[5] La Antropología de esta Enciclopedia posee un aspecto ampliamente fenomenológico, en la medida en que Hegel presenta en primer plano los elementos del contenido natural del alma y su transformación a través de relaciones transversales y reticulares entre sí. Ello no significa que olvidemos las relaciones entre Antropología y Lógica, fundamentales para la comprensión adecuada de toda esta Sección. En efecto, la fenomenología propiamente dicha se encuentra en la Sección B de la Filosofía del espíritu subjetivo, dedicada a la conciencia. 
como identidad inmediata de la subjetividad que es en sí y de la corporeidad. Esto, a su vez indica, en términos generales, una unidad inmediata de alma y corporeidad, en la cual no tiene cabida la disociación entre ambas defendida por el pensamiento moderno. Porque el hecho de que Hegel caracterice el alma como «sustancia» (\$309) no tiene un significado precrítico, sino que alude a su actividad gracias a la cual el alma "progresa» desde su vinculación con la naturaleza hasta su propia configuración. ${ }^{6}$ Asimismo, la diferenciación entre el alma y el espíritu ${ }^{7}$, siempre operativa, no supone una reformulación dualista, ni una contraposición de elementos o cosas independientes.

De hecho, Hegel aborda el problema del dualismo y su significado filosófico: «La cuestión acerca de la inmaterialidad del alma puede tener aún un interés si por un lado se representa la materia como algo verdadero y el espíritu, por otro lado, como una cosa» (\$309n). Desde esa perspectiva, la física de su tiempo daba cabida a ciertas «sustancias imponderables» como la luz y el calor, dotadas de un Daseyn sensible ( $\$ 309 \mathrm{n})$, pero que no incluían en ellas algo inmaterial. A esta consideración física de la inmaterialidad opone Hegel que «en la idea de la vida ya está superado de por sí (an sich) el ser-fuera-de-sí de la naturaleza y el concepto de su sustancia» (l. c.). ${ }^{8}$ Por lo tanto, es preciso no cosificar al alma como algo dado en la naturaleza material. Además, el problema de la relación entre ambos o, más exactamente, «la cuestión de la comunidad del alma y del cuerpo», se tomaba como un hecho que había que conceptualizar» (\$309n), sin encontrar para ello una formulación satisfactoria. «Pues de hecho, cuando ambos se presuponen como independientes y contrapuestos, son recíprocamente impenetrables, lo mismo que cada materia es impenetrable frente a cualquier otra y es considerada como el no ser de la otra...» (l. c.). Hegel menciona algunas respuestas de la filosofía moderna (Descartes, Malebranche, Spinoza o Leibniz), que a su juicio no llegaron a una conceptualización antropológica plenamente independiente.

El alma se presenta en distintos niveles de realización y desarrollo, pero su realidad efectiva se pone de manifiesto en cuanto corporeidad. El esquema

[6] En el Esbozo de sistema (Systementwurf) II, de 1804-1805, Hegel afirma que el alma «es sustancia, pero sustancia que no es solamente la diferencia de los accidentes que fueran puestos en ella» «y la sustancia es más bien sujeto...» (GW 8, 140). Cf. M. C. Paredes-Martín, «Hegel. Periodo de Jena (1801-1806)», en G. Amengual, ed., Guía Comares de Hegel, o. c., p. 65.

[7] Sobre el lugar sistemático de «espíritu» y su relación con el concepto de «alma», cf. W. Jaeschke, «Der Geist und seine Wissenschaften», en Geist? II, Hegel-Jahrbuch 2011, Berlin, Akademie V., pp. 12-13.

[8] Sobre la idea de «vida», cf. M. Álvarez Gómez, «Concepto de vida en Hegel», en Atilano Domínguez (ed.), Vida, pasión y razón en los grandes filósofos. Cuenca, Universidad Castilla La Mancha, 2002, pp. 165-179. 
de este desarrollo en la Enciclopedia de 1817 avanza ciertas similitudes con las ediciones posteriores, aunque tanto las diferencias terminológicas, como sobre todo, de contenido, no nos permiten en este trabajo establecer una comparación entre ellas. La determinidad natural del alma se parece al «alma natural» de las ediciones posteriores, pero no así la siguiente caracterización, que es aquí la del alma en su oposición frente a su falta de conciencia («el alma que sueña», en 1827 y «el alma que siente», en 1830). No obstante, lo decisivo es que el primer momento, «la determinidad natural del alma», que es el universal, conduce al segundo momento: «oposición del alma subjetiva frente a su sustancialidad», que es el particular, y éste conduce al tercer momento: «la realidad efectiva del alma», que es el individual.

\section{EL ALMA ES FUNDAMENTO DE PARTICULARIZACIÓN Y DE SINGULARIZACIÓN}

Como hemos indicado, junto con la idea de inmaterialidad partimos de que «en la idea de la vida» la naturaleza no es algo meramente exterior ni el alma es algo meramente interior; por lo tanto, no existe una oposición entre lo material y lo inmaterial. Ello está relacionado con la noción de Naturgeist, que Hegel introduce desde el comienzo. El espíritu en cuanto alma natural abstracta es este «ser inmediato, hundido en la naturaleza» (\$310). Esta expresión, tan conocida, tiene un significado menos metafórico de lo que parece, puesto que depende de que «el espíritu ha devenido como verdad de la naturaleza» y «el espíritu devenido tiene por tanto el sentido de que la naturaleza se supera ella misma de por sí (an ihr selbst) como lo no-verdadero» (\$308). Hegel lo compara con «el nus de los antiguos» $(\$ 311)^{9}$, y lo relaciona con la vida planetaria universal, así como con las características geográficas de la Tierra -tal como lo hará posteriormente-. En este sentido, el surgimiento del alma está en conexión con el desarrollo de la vida y se produce cuando la naturaleza se opone a su existencia material y se separa de la ubicuidad de su materia. El alma, en su mediación entre el espíritu y la naturaleza, no se desprende nunca de ésta en sus diferentes transformaciones; ahora bien, en tanto que el espíritu ha devenido como «verdad» de la naturaleza, la independencia de ésta es posible en cuanto puesta por el espíritu mismo, de modo que el ser-puesto de la naturaleza forma parte asimismo del significado de Naturgeist.

En un texto que prácticamente se mantiene hasta la edición de 1830, Hegel afirma que el alma «en cuanto en general [es] de por sí (an sich) el concepto, está singularizada en el sujeto individual. Pero esta subjetividad se considera

[9] Sobre esto, cf. por ejemplo, F. Chiereghin, «Das griechische Erbe in Hegels Anthropologie», en Hespe, F./Tuschling, B., Psychologie und Anthropologie oder Philosophie des Geistes, Stuttgart-Bad Cannstatt, Frommann-Holzboog, 1991, pp. 9-51. 
aquí solo en cuanto singularización de las determinidades naturales; ella es en cuanto modus de los diversos temperamentos, caracteres, fisionomía y otras disposiciones de familia o de individuos singulares» (\$314 cf. E1830: \$395). La singularización es el punto de partida de una subjetividad que solo tiene algunas características naturales, ciertas modalidades de temperamento y formas de relacionarse con lo exterior. Por lo tanto es una subjetividad emergente, dotada de una capacidad de transformación. Las determinidades naturales forman el contenido del alma individual que está sujeta a las contingencias de la naturaleza inmediata y a sus vicisitudes. Es de notar que el alma, en cuanto comienza a estar singularizada en una subjetividad que tan solo es modus de diversos caracteres etc., no posee «facultades» propiamente dichas y esto indica que Hegel, como en años anteriores, sigue entendiendo la subjetividad como la integración, más o menos concreta y diferenciada, de diversos modos de pensamiento y disposiciones.

El comienzo de esta singularización viene caracterizado como un despertar del alma desde la vida natural no consciente (cf. \$315). Toda la actividad del alma proviene de este despertar y va a estar orientada a sucesivos despertares, hasta el despertar de la conciencia (cf. (\$307): primero, como alma natural, luego, como alma que, por así decirlo, se siente a sí misma y, finalmente, como el alma en su realidad efectiva. El tema del despertar a la actividad consciente está presente en Hegel ya en el manuscrito "Zur Psychologie und Transzendentalphilosophie» ${ }^{10}$, de 1794, que fue publicado por Hoffmeister como «Materien zu einer Philosophie des subjektiven Geistes». En este texto fragmentario, que cabe considerar como un temprano acercamiento a la filosofía trascendental de Kant ${ }^{11}$, Hegel esquematiza el surgimiento de representaciones en las que no interviene la conciencia y por lo tanto dependen de la fuerza del alma para producirlas. Lo que Hegel llama «la mera obra del alma», sin recuerdo (cf. GW1, 172), tiene causas muy variadas: desde la disposición física del cerebro junto con otros factores fisiológicos hasta la memoria lingüística o las capacidades para relacionar «el todo y las partes». Pero es sobre todo una especie de despertar del alma -que da lugar a la Wiedererwekung der Vorstellungen (GW1, 175ss)- lo que parece responsable de una cierta autonomía del alma natural.

En la Enciclopedia de 1817, el alma despierta desde la vida natural no consciente. Este despertar sacude el vínculo inmediato con la naturaleza en el que el alma se mantiene encerrada en sí misma, o no presente a sí misma. Hegel afirma que el despertar es «el juicio inmediato del alma singular mediante el cual se enfrenta a la vida natural no consciente» (\$315), y al sueño. Ahora bien,

[10] G.W.F. Hegel, Frühe Schriften, GW 1, pp. 167-192.

[11] Cf. Ma. del C. Paredes-Martín, «El joven Hegel», en G. Amengual, ed., Guía Comares de Hegel, p. 16. 
el despertar no se diferencia del sueño de una manera extrínseca, sino en el seno de la vida natural del alma. Porque la vida del alma está hecha de sueño y vigilia. El hecho de que la diferencia entre el sueño y la vigilia no represente una contraposición indica que existe entre ambos una unidad natural subyacente y que su diferenciación ocurre dentro de la actividad viviente del alma, de la que proviene la fuerza del despertar. Significativamente, Hegel afirma que el despertar no es algo meramente diferente «para nosotros» y que el sueño es un «reforzamiento» o «vigorización» (Bekräftigung) de la actividad consciente del espíritu, que se produce en la vigilia (\$316). Podemos decir que el alma hace esta primera distinción dentro de sí misma, con la que «despierta» a su poder de diferenciarse a sí misma. El juicio inmediato, que es el despertar del alma singular (cf. $\$ \$ 315$ y 316) no es una ruptura total, sino la separación paulatina de la dependencia de la naturaleza.

Hegel propone así una breve filosofía del despertar, en el que éste se distingue del sueño como el ser-para-sí del alma (cf. \$318) respecto de su contenido natural. El juicio inmediato es ya un acto de disociación del alma respecto de su unidad simple y de su universalidad indiferenciada. ${ }^{12}$ El despertar y el sueño no se corresponden aquí explícitamente con la actividad y la pasividad, porque el sueño, como reforzamiento de la actividad -y no como «quietud» de la misma-, es visto como «regreso desde el mundo de las determinidades» y mantiene al alma «en el ser universal de la subjetividad, que es el poder absoluto» (\$316). Según esto, la identidad del alma contiene la diferencia entre el sueño y la vigilia; esta diferencia, y sobre todo el «regreso» (Rükkehr) a lo indeterminado, contribuye a hacer comprensibles ciertas observaciones de Hegel sobre las «enfermedades» del alma.

\section{LA OPOSICIÓN DEL ALMA SUBJETIVA FRENTE A SU SUSTANCIALIDAD III. 1 EL SENTIMIENTO DE SÍ}

Sobre lo anterior podemos hacer las siguientes consideraciones. Por una parte, el alma que hace la distinción entre sueño y vigilia no es (o no parece ser) capaz de delimitar sus propios contenidos y se afana por conseguir una subjetividad que todavía no logra, ya que sus relaciones se insertan en «la relación abstracta universal a su vida natural» (\$320). Por otra parte, el espíritu oscila entre su condición primera de espíritu natural y su realidad efectiva racional, que aún no tiene una auténtica presencia.

[12] Nos hemos ocupado ya extensamente del significado de juicio (Urteil) en Hegel, especialmente en los años de Frankfurt: cf. por ejemplo, M. C. Paredes-Martín, «El joven Hegel», en G. Amengual, ed., o. c., pp. 20ss; Génesis del concepto de verdad en el joven Hegel, Salamanca, 1987, pp. 116ss. 
No obstante, el momento de diferenciar entre el sueño y la vigilia ya es una sensación primordial. El alma natural se percibe desde el estar despierto, porque es como se siente a sí misma ${ }^{13}$, tanto interna como externamente. A partir de aquí se pone de manifiesto el avance del alma hacia la singularidad y el despliegue de los contenidos que encontramos en nosotros mismos, en el ámbito del sentimiento. ${ }^{14}$ Hegel lo especifica de este modo: «La singularidad efectiva (wirkliche Einzelnheit) como reflexión del alma en sí es su ser-para-sí que está despierto en la corporeidad orgánica definida; el sentimiento de sí determinado en sí y para sí incluso idéntico con la corporeidad, la sensación interna y externa» (\$318). La singularidad efectiva es el sujeto aún no completamente perfilado al que aludíamos antes, lo cual contrasta con el carácter «definido» o completo de la corporeidad orgánica.

Por lo tanto, la singularización del sujeto viviente ${ }^{15}$ guarda alguna similitud con lo que será el planteamiento sobre «el alma que siente» en 1830. Hegel advierte que todo lo que expone sobre este tema hay que tomarlo como una anticipación, en especial lo que afirma sobre la vigilia como algo específico del desarrollo del espíritu. Además, esta primera oposición del alma subjetiva a su sustancialidad hace de ella un sujeto, en cuanto ser-para-sí, aunque no llegue aún a establecer una relación sujeto-objeto como tal. Para Hegel, la partición que supone el juicio inmediato del alma es una primera reflexión-en-sí que es a la vez reflexión-en-otro, y esto hace que el alma se encuentre en referencia (Beziehung) negativa consigo misma (cf. \$319).

Hegel no prescinde, por lo tanto, de la negación para exponer todo este proceso. El alma entra en relación negativa con su ser natural en el momento en que comienza la reflexión y esto no es una actividad particular de carácter empírico, sino que forma parte del carácter dialéctico inherente al desarrollo de este concepto. Porque «en la metafísica más reciente, el espíritu en cuanto alma [...] se ha convertido en una cosa con muchas propiedades y fuerzas» $(\$ 321 \mathrm{n})$, o bien se ha presentado en una configuración fantasmagórica. La metafísica se ha quedado aferrada en la determinación abstracta "cosa» y ha sometido al alma a «las determinaciones del ser, de la cualidad y la cantidad y a todas las determinaciones de la reflexión de una sustancia singular, de causa,

[13] Cf. Aristóteles, De Anima III, 415a, ss.

[14] Sobre el alcance de la sensación y el sentimiento, cf. A. Arndt, «Zur Rolle des Gefühls in Hegels Theorie des subjektiven Geistes», en A. Arndt/J. Zovko, Hegels Anthropologie, Berlin/ Boston, De Gruyter, 2017, pp. 75-88.

[15] El movimiento de la Antropología, como el proceso de la forma del ser a la forma de la esencia, ha sido estudiado por H.-Ch. Lucas: “'Die souveräne Undarkbarkeit' des Geistes gegenüber der Nature", en Hespe, F./Tuschling, B. Psychologie und Anthropologie oder Philosophie des Geistes, Stuttgart-Bad Cannstatt, 1989, p. 273. 
etc.; y aquí es donde ha tenido interés la pregunta por la sede del alma, por la comunidad de esta cosa con las otras cosas, con el cuerpo» (íbid.). Frente a esta representación, para Hegel lo característico del alma, en cuanto dotada de actividad (cf. \$309), es oponerse a su contenido natural y así llevar a cabo su progresiva diferenciación. Los diversos temperamentos, caracteres, impulsos, sensaciones internas complejas, así como emociones y disposiciones de familia no son determinaciones de la reflexión ni características empíricas meramente dadas, sino resultados de mediaciones en las que se plasma «la inmanencia del espíritu individual en su corporeidad» $(\$ 318 n)$

\section{2 LOS CONFLICTOS DEL ALMA}

El alma progresa desde la individualidad natural a la individualidad interior, esto es, de la individualidad abstracta al ser-para-sí y hacia el yo. ${ }^{16}$ Por ello, no es casual que Hegel, a pesar de las diferencias entre su antropología especulativa y la antropología empírica de Kant, elogie la aportación de la filosofía crítica por "haber liberado a la metafísica del espíritu como cosa», y a la inversa, por haber liberado al espíritu «de esta metafísica y de esta representación y haber puesto en su lugar al yo» (\$321n). ${ }^{17}$ Los modos del alma comprenden todas las situaciones anímicas de la vida humana, hasta las más variadas formas anómalas que alteran su convivencia natural con el espíritu y con el cuerpo, como los «presagios», el «sonambulismo» y el «magnetismo animal». El alma participa también en toda esta «relación mágica» (\$320n) y permanece sometida a tales fenómenos y a otras condiciones que pertenecen a la esfera del sueño. ${ }^{18}$ Por lo que respecta al espíritu, éste que «como tal tiene lo universal como objeto suyo en cuanto algo pensado» (\$320n), experimenta en esas alteraciones un rebajamiento (Herabsetzung) de la autoconciencia libre, una desviación (Scheidweg) de sí y una recaída en la contingencia.

Pero los estados que ponen al alma en esas condiciones no solo se refieren al sueño, sino que abarcan toda la actividad anímica. En esta mezcla de situaciones y en este círculo de particularidades en que el alma barrunta su interioridad, pero no trasciende a su esencia, Hegel se refiere a la locura, como una relación de contradicción turbadora en la que el alma vive su identidad inmediata como

[16] Esto se hace evidente en las posteriores elaboraciones de la Antropología, cf. Jaeschke, W. Hegel-Handbuch, 2. Auflage, Stuttgart-Weimar, 2010, p. 354.

[17] Hegel se centra en la concepción kantiana del yo frente a la identificación entre el yo y la «cosa que piensa» en la metafísica moderna. Más adelante, sin embargo, Hegel criticará la teoría kantiana de la conciencia. Cf. \$332n.

[18] Es de notar que en la Enciclopedia para los últimos cursos del bachillerato, (1808-1816) Hegel menciona el sonambulismo en el contexto de los sueños. Cf. Philosophische Enzyklopädie für die Oberclasse, TW, 4, \$152.. 
una oposición y a la vez la oposición misma como una identidad. Para el espíritu, esta contradicción y la oscilación entre su condición primera de espíritu natural y su realidad efectiva racional equivale a lo que Hegel considera un regreso a fases anteriores del desarrollo del alma. El «círculo mágico» que envuelve la vida simpática favorece la enfermedad del espíritu, cuando éste queda desposeído de su capacidad de autorreferencia pensante y a merced de cualquier desviación. ${ }^{19}$

En el $\$ 321$ sobre la locura, Hegel destaca la relación de contradicción que es condición de la locura y resultado de la ruptura de la identidad del alma con su ser natural particular. Se produce entonces una relación «no-verdadera» $(\$ 321 n)$, que tiene existencia solo como condición de la enfermedad del espíritu. Es muy significativa la referencia aquí al juicio y al silogismo formal del entendimiento, cuyos momentos solo tienen un modo de ser concreto violento (ein gewaltsames Daseyn) que está fundado en una destrucción. Seguidamente, Hegel advierte sobre las consecuencias de entender el espíritu como una "cosa», cuya crítica ya hemos mencionado; de ahí que destaque «el mérito de Kant» por haber puesto al yo como centro de la subjetividad. En tercer lugar, Hegel se refiere a las variedades de la «locura» y a lo absurdo que es «querer elaborar el conocimiento del hombre a partir de ellas» (íbid.), o como si se tratara de delitos y depravaciones. Para Hegel las diversas situaciones de la locura contienen mucho de indeterminado; por lo tanto, no se trata de contraponer la normalidad a la anormalidad, puesto que sus condiciones y sus estructuras subyacentes son en muchos casos compartidas. La contradicción no existe solo en el alma trastornada; más bien, ciertas contradicciones son esenciales para el desarrollo del alma, lo que no significa que todas las contradicciones sean iguales. La base de la contradicción vivida en la locura se encuentra en que «el alma subjetiva como tal rompe esa identidad inmediata, sustancial, de la relación con su ser natural particular» (\$321).

Por ello, la locura no depende de una "pérdida de entendimiento» ni de una "pérdida de razón", sino de una determinada contradicción del espíritu que es una «desgracia absoluta» ( $\$ 321 \mathrm{n}$ ), ya que el espíritu queda sometido a una cosificación alienante y despojado de su verdadero ser. Aquí, Hegel anticipa la noción de espíritu como «la identidad libre de lo subjetivo y lo objetivo» (íbid.), es decir, lo considera desde un estadio que el propio Hegel aún no ha

[19] De nuevo, en el texto de 1794 sobre Psicología y filosofía trascendental encontramos diferentes clases de sueño (Schlaf), los sueños (Träume), el sonambulismo, las ensoñaciones y alucinaciones, visiones de toda índole y la locura en sus distintas acepciones (GW 1, pp. 178s, 181s, 183s). También en la Enciclopedia para los últimos cursos del bachillerato (1808-1816) Hegel menciona la locura como uno de los estados extraordinarios del espíritu. 
elaborado y que sólo tratará mucho después (cf. \$364), en la tercera sección del «Espíritu subjetivo» (C. Geist). Esto es interesante porque Hegel apela a una noción de espíritu que corresponde a un desarrollo ulterior de la conciencia, si bien desde la perspectiva del alma la locura aparece antes del tratamiento específico de la conciencia.

En definitiva, la locura es «captar el destino puramente como destino ciego, es decir, como extrañeza absoluta frente al concepto y no obstante como idéntico consigo, saberlo en unidad como lo suyo y como lo no suyo» (íbid.). Se acentúa entonces el hecho de que la relación entre el alma y el espíritu queda trastocada y se transforma en una tensión alienante. Es una inversión (Verkehrung) de las relaciones que configuran el temperamento, las disposiciones y los diversos modos del alma que tejen sus relaciones con el mundo. Y, en general, la locura es una "destrucción» de la identidad del alma y de su capacidad de mediación entre la naturaleza y el espíritu. En este escenario también se pone de manifiesto que la vida del alma es cambiante, pues no solamente se despliega hacia nuevos estadios más elevados, sino que retiene su historia pasada y retrocede a estadios anteriores; se desvía y disuelve en lo que podríamos llamar estados de ánimo desestructurados y «momentos no-verdaderos».

El espíritu, en cuanto modalización del yo, experimenta los conflictos del alma. Pero también en esta desviación el espíritu ejerce su actividad para revertir la fijación de estos desvaríos. Esto no significa que la cordura triunfe siempre; antes bien, nos pone ante la posibilidad de su superación, del mismo modo que el alma está abierta y expuesta a la realidad de su desviación. ${ }^{20}$ Hegel sostiene que «la representación de una "condición primitiva del ser humano» (\$320) dista mucho de corresponder a la experiencia que efectivamente constituye la vida del alma. En esta interesante Nota al \$321, se muestra que la locura y «todas esas formas de enfermedad» son procesos y experiencias de lo extraño, y no tanto pérdidas de facultades, antes bien, todas las formas de locura están relacionadas entre sí y adolecen de una resistencia a la mediación que articula la fluidez de la subjetividad en su dimensión antropológica.

\section{Alma y CORPOREIDAD}

Esta concepción del alma no puede comprenderse sin la corporeidad puesto que, como hemos visto, en todos los estados están implicados tanto el alma, como el cuerpo y el espíritu natural. En el nivel del sentimiento y en general de «la vida simpática» el alma se siente en convivencia con la corporeidad (cf.

[20] Se pueden aducir diversos motivos para la atención de Hegel a la locura: por ejemplo, su recuerdo de Hölderlin, el gran amigo de juventud, y la enfermedad psíquica de su hermana Christiane. Asimismo, en su carta a Windischmann de 27.5.1810, Hegel se refiere a ciertos problemas de hipocondría. Cf. Briefe I, p. 314. 
$\$ 318 \mathrm{n}$ ), mientras que el espíritu se encuentra limitado, sometido y no libre, pero no alienado. Esta situación de relativa convivencia se «rompe» cuando no hay capacidad de juicio y el alma es incapaz de conservar su identidad.

Una reconsideración del alma en cuanto «identidad inmediata» con la corporeidad» (cf. \$309) nos lleva ahora a entender el «despertar» como el comienzo de la transformación del cuerpo desde su mera materialidad. Asimismo, el «despertar» no podría ser una sensación primordial para el alma si ella no estuviera corporalizada. La corporeidad posibilita, pues, la mediación entre el alma universal y la sensación singular, a través de la particularización de sus modos o capacidades. Si bien en la sección dedicada al alma Hegel no entra en detalles sobre este tema, el esquema general lo encontramos antes, en la parte de la «Filosofía de la naturaleza» dedicada al organismo animal (cf. \$281, 282 y $282 n)^{21}$ y al que el propio Hegel se remite. No obstante, la diferenciación entre el organismo animal y la corporeidad humana es clara desde el momento en que estamos en el ámbito del espíritu subjetivo y su actividad es una liberación de los condicionamientos naturales. ${ }^{22}$ Por ello, la vigilia es asimismo «un estar despierto específico del espíritu» (\$318n), en tanto que «en el aspecto natural de esta inmanencia del espíritu individual en su corporeidad reside ante todo su sano convivir simpático (sympatische Mitleben) con ella» (íbid.), al que pertenecen también las emociones y su manera específica de ser sentidas y de estar corporeizadas.

Para Hegel, «un tratamiento hostil y devastador de la corporeidad la convertiría más bien en una objetividad negativa frente al sujeto» (\$323). Porque el alma se expresa en su corporeidad en acciones repetidas que van creando su fisonomía. Estas acciones se producen sobre todo en la vigilia, ya que están determinadas por su finalidad (\$325). Además, la actividad del alma no está dirigida hacia la corporeidad como hacia un objeto externo, porque es la destinación natural de su relación íntima con la naturaleza. Consiguientemente, si por un lado al ser el alma espíritu natural, lo espiritual sigue permaneciendo vinculado a la naturaleza, por otro lado, en la corporeidad la naturaleza se transforma hasta llegar a ser expresión del espíritu natural.

Esta transformación del cuerpo no es inmediata y requiere un despliegue de ciertas actividades. El alma es «la sustancialidad, el poder y el destino de la otra realidad efectiva» (\$322) y se manifiesta en la capacidad de configurarse en el cuerpo material, el cual a su vez responde a este proceso de transfor-

[21] Cf. De Anima, 412 a, 21-27.

[22] Las interpretaciones naturalistas de la antropología hegeliana suelen dejar de lado el marco conceptual en el que se integra su filosofía del espíritu subjetivo. En el mismo sentido, cf. B. Sandkaulen, «Kant und Hegel über die Seele», en A. Arndt, B. Bowman, M. Gerhard y J. Zovko, eds. Hegels Antwort auf Kant I, Hegel-Jahrbuch (2016), p. 22. 
mación. El hábito y la «repetición de acciones determinadas» son un punto fundamental de la relación entre el alma y la corporeidad, aunque este tema no está desarrollado en la primera Enciclopedia. La forma de la repetición aparentemente no añade nada a las acciones que se repiten, pero la repetición misma configura el modo de expresarse del alma así como su huella externa en el mundo. En este sentido, la repetición es una forma de experiencia mediada, una «destreza» (Geschicklichkeit) o habilidad del alma para proyectar sus intenciones y propósitos sobre el cuerpo y hacer de éste un instrumento para sus fines. Precisamente, como hábito determinado, la destreza libera al alma de su determinación por la materialidad de su cuerpo y le permite construir idealmente su comportamiento (cf. \$325).

La destreza del hábito tiene un significado vinculado a la fase de desarrollo en que se encuentre la convivencia del alma con su corporeidad. A medida que se hace más intensa esta convivencia, el alma actúa más libremente y se pone más de manifiesto para ella la comunidad entre ambas. Por ello, «el alma es en su corporeidad bien desarrollada (durchgebildeten) como sujeto singular y ésta [es] la exterioridad de aquella como predicado» (\$326). Se da, por lo tanto, una referencia recíproca y aunque no es una relación simétrica, la corporeidad representa al alma y así se hace signo de ella. Todo el movimiento del desarrollo del alma natural hasta su singularización en una corporeidad propia, viene a resumirse de este modo:

«La actividad del alma frente al cuerpo es más bien la de poner su identidad siendo de por sí (an sich seyende Identität) con su corporeidad, la de superar solo la forma de la inmediatez de esta unidad y la de ser, en cuanto alma universal que penetra en su cuerpo para sí, sujeto en él mismo como en el predicado» (\$324).

Así, la convivencia entre el alma y su cuerpo adquiere cotas cada vez más altas de idealidad. Primero, el cuerpo como instrumento conserva cierta exterioridad, y el alma se recuerda en su cuerpo de modo que, por una parte, «es esta identidad suya con él»y, por otra parte, «tiene su ser en él»(\$325). Ahora bien, esta identidad y este ser no son inmutables, ni están dados de modo inmediato, sino que avanzan en la interiorización de la exterioridad instrumental. Aunque brevemente, Hegel da cuenta de la transformación del cuerpo por parte del alma al convertirlo en signo de ella. El signo modifica la relación del alma con su ser natural particular, pero a la vez es una nueva identidad puesta por el alma misma. La exterioridad como signo es un universal y el alma, que es para sí en su cuerpo, como en su signo, gracias a la corporeidad es este sujeto singular.

La identidad de lo interno y de lo externo es el logro de esa interiorización. El cuerpo se hace signo del alma y el alma tiene su figura libre en su corporeidad (cf. \$326). En este sentido, el cuerpo es signo ante todo para el alma, que encuentra en él una exterioridad plenamente constituida, y a la vez es signo 
para el espíritu, que tiene en la corporeidad una representación oblicua y limitada. El signo representa al espíritu, pero no como él es para sí, sino como algo distinto, como «otro». «El espíritu es, pues, en este signo suyo, sencillamente finito y singular» (\$326n). Desde el punto de vista de la experiencia, el alma se hace humana en su cuerpo y el cuerpo se hace cuerpo humano gracias al alma. Entonces, ciertas experiencias del alma se traducen en formas y gestos corporales que son expresión del ser humano: la mano, la voz, la sonrisa, el llanto, la palabra, etc... La figura humana reúne en sí misma una doble consideración: desde la perspectiva natural, es la más elevada y desde la perspectiva del espíritu es «la aparición primera (die erste Erscheinung) del mismo», porque es «su primera realidad efectiva, aún hundida en la esfera de la inmediatez» (íbid.).

El final de la Sección del alma expone así el punto central de la Antropología de Hegel: la realidad efectiva del alma (die Wirklichkeit der Seele). No solamente la mano y los gestos son expresión de las experiencias del alma, también la voz y «el tono espiritual» (íbid.), ponen de manifiesto que el cuerpo es la exterioridad de una naturaleza superior. El alma llega a ser efectivamente real en su cuerpo debido a que se configura en él, y en su corporeidad tiene su figura libre. La expresividad del cuerpo es humana, precisamente en este sentido; porque en él alcanza el alma su configuración más genuina. Pero con ello, también, el alma transforma el sentimiento de sí en un nivel superior: deja de ser alma para ser «yo». Esto es, supera su presencia inmediata a sí, se conserva a sí misma como alma natural y como alma dotada de sentimiento, para captar su propia subsistencia en unidad con su cuerpo.

El alma ha cumplido su desarrollo y es ahora sujeto para sí misma. Por ello, «la materia no tiene en sí y para sí ninguna verdad en el espíritu en cuanto alma universal» (\$327) y la corporeidad no puede ofrecer resistencia a su conformación (Einbildung) por parte del alma. El alma a su vez, al haber opuesto a sí misma su ser, ha perdido la inmediatez de lo que significa el espíritu como alma. Dicho de otro modo, el alma pierde su significado natural a medida que va adquiriendo realidad efectiva en la humanización de la corporeidad. Hegel afirma que «el juicio en el que el sujeto es yo, frente a un objeto, como un mundo externo a él, de modo que sin embargo es reflejado en él mismo inmediatamente, es la conciencia» (\$328). Antes, el espíritu natural estaba limitado por la necesidad propia de las determinaciones naturales y ahora el alma que ha llegado a su realización efectiva con la corporeidad no alcanza aún la esfera de la conciencia. Para referirse a esta transición, Hegel habla de nuevo de «un despertar más elevado» en el que la infinitud del espíritu se muestra como referencia de sí mismo consigo mismo. La materia de por sí no tiene ninguna verdad en el espíritu si nos quedamos anclados en su estricta materialidad, y éste es otro de los aspectos que muestra el itinerario del alma hacia su nuevo despertar como conciencia. El juicio original (Ur-teil) del alma mediante el cual 
ésta se ponía en relación negativa consigo misma ha propiciado otros juicios hasta llegar a este paso decisivo: un juicio esencialmente diferente en el que el sujeto excluye la totalidad de sus determinaciones como objeto, es decir, «un mundo externo a él», con el cual sin embargo se relaciona de tal modo que en él se refleja inmediatamente en sí mismo.

Hegel ha resuelto parcialmente algunas dificultades inherentes a este desarrollo del alma y de la actividad del espíritu para liberarse de la alteridad de la naturaleza. Ha mostrado que el alma posee identidad y unidad ya en los niveles naturales del sentir y en el contenido universal de sus «modos», unidad que es lógicamente anterior a su concreción en un yo y que es, por lo tanto, unidad pre-objetiva. El desarrollo del alma haciéndose a sí misma a través de la corporeidad nos muestra al cuerpo como instrumento y en este sentido se evidencia el eco de los antiguos, especialmente, de Aristóteles. ${ }^{23}$ Pero al introducir Hegel desde el comienzo la noción moderna de espíritu y la mediación del alma entre el espíritu y la naturaleza, la deuda con Aristóteles se transforma al integrarse en un marco conceptual especulativo, que parte de la exigencia del desarrollo y la profundización en una noción de subjetividad moderna y genéticamente postkantiana. Esta profundización no transita por un único camino. El ser-para-sí del alma se abre paso a través de su vida no consciente, y en este sentido, «avanza» hacia formas de aprehensión cada vez más complejas, pero también «retrocede» y sucumbe a la desviación más oscura del espíritu finito.

Así Hegel muestra que los caminos de la formación de la subjetividad no siempre son caminos de construcción. Y no obstante, la destrucción misma forma parte de la construcción del yo. El carácter limitado de este tratamiento antropológico del alma en la Enciclopedia de 1817 será repensado por el propio Hegel y sometido a profundas reelaboraciones en las ediciones posteriores.

\section{REFERENCIAS}

Álvarez-Gómez, M. «Concepto de vida en Hegel», en Atilano Domínguez, ed., Vida, pasión y razón en los grandes filósofos. (ed.) Cuenca, Universidad Castilla La Mancha, 2002, pp. 165-179.

, «La personalidad como vida en la verdad», en J.I. Falgueras, J. A. García, J.J. Padial, eds. Yo y tiempo. La antropología filosófica de G.W.F. Hegel, Málaga, Contrastes. Suplemento 15 (2010), Univ. de Málaga, 25-42.

Amengual, G. «La Enciclopedia de las Ciencias Filosóficas», en G. Amengual, (ed), Guía Comares de Hegel, Granada, Comares, 2015, 97-109.

[23] Cf. De Anima, 415b 19. 
Arndt, A., «Zur Rolle des Gefühls in Thegels Theorie des subjektiven Geistes», en Hegels Antropologie. Hegel-Jahrbuch 9, eds. A. Arndt y J. Zovko, Berlin/ Boston, de Gruyter 2017, 75-88.

DeVries, W. A., Hegel's Theory of Mental Activity, Ithaca, Cornell University Press, 1998.

Falgueras, J.I., García, J. A. , Padial, J.J. eds. Yo y tiempo. La antropología filosófica de G.W.F. Hegel, Málaga, Contrastes. Suplemento 15 (2010) Univ. de Málaga.

Halbig, Ch. Objektives Denken. Erkenntnistheorie und Philosophy of Mind in Hegels System, Stuttgart Bad-Cannstadt, Frommann-Holzboog, 2002.

Hespe, F., Tuschling, B. Psychologie und Anthropologie oder Philosophie des Geistes, Stuttgart-Bad Cannstatt, Frommann-Holzboog, 1991.

Jaeschke, W., «Anthropologie und Personalität», en Hegels Anthropologie. Hegel-Jahrbuch 9, eds. A. Arndt y J. Zovko, Berlin/Boston, de Gruyter 2017, 1-16.

, «Der Geist und seine Wissenschaften», en Geist? II, Hegel-Jahrbuch (2011), Berlin, Akademie V.

LuCAs, H.Ch., “'Die souveräne Undarkbarkeit' des Geistes gegenüber der Nature", en Hespe, F./Tuschling, B. Psychologie und Anthropologie oder Philosophie des Geistes, Stuttgart-Bad Cannstatt, 1989, pp.

Nuzzo, A., «Anthropology, Geist, and the Soul-Body Relation. The systematic Beginning of Hegel's Philosophy of Spirit», en Stern, D., Essays on Hegel's Philosophy of Subjective Spirit, Nueva York: SUNY, 2013, pp. 1-17.

PADIAL, J.J. «Subjetividad y separación. La crítica del joven Hegel a la separación de facultades y a la soledad ontológica», en J.I. Falgueras, J. A. García, J.J. Padial, eds. Yo y tiempo. La antropología filosófica de G.W.F. Hegel, Málaga, Contrastes. Suplemento 15 (2010), pp. 113-128.

Paredes-Martín, M. C. «El joven Hegel», en G. Amengual, ed., Guía Comares de Hegel, o. c., pp. 1-31.

"«Hegel. Periodo de Jena (1801-1806)», en G. Amengual, ed., Guía Comares de Hegel, o. c., pp. 33-71.

, «La conciencia en la Enciclopedia de 1817», Revista Opiniao Filosofica, v. 8, n. 2 (2018), pp. 85-103.

SandKaulen, B. «'Die Seele ist die existierende Begriff'. Herausforderungen philosophischer Anthropologie» Hegel-Studien 45 (2010), pp. 35-50.

, «Kant und Hegel über die Seele», en Hegels Antwort auf Kant I, HegelJahrbuch (2016), eds. A. Arndt, B. Bowman, M. Gerhard y J. Zovko, pp. 15-23.

SieP, L., «Leiblichkeit, Selbstgefühl und Personalität in Hegels Philosophie des Geistes», en L. Eley ed., Hegels Theorie des subjektiven Geistes, Stuttgart Bad-Cannstadt, Frommann, 1990, 203-220. 
Wenning, M., «Awakening from Madness. The Relatioship between Spirit and Nature in Light of Hegel's Account of Madness», Stern, D., Essays on Hegel's Philosophy of Subjective Spirit, Nueva York: SUNY, 2013, pp.107-120. 
